\title{
Understanding the Correlates of Face-to-Face and Cyberbullying Victimization among U.S. Adolescents: A Social-Ecological Analysis
}

\author{
Jun Sung Hong \\ Wayne State University, Detroit, MI \\ Sungkyunkwan University, Seoul, Republic of Korea \\ Jungup Lee \\ Florida State University, Tallahassee, FL \\ Dorothy L. Espelage \\ University of Illinois, Urbana-Champaign, IL \\ Simon C. Hunter \\ University of Strathclyde, Glasgow, United Kingdom \\ Desmond Upton Patton \\ University of Michigan, Ann Arbor, MI \\ Tyrone Rivers, Jr. \\ University of Illinois, Urbana-Champaign, IL
}

Jun Sung Hong, Assistant Professor, Email: f14684@ wayne.edu, Phone: 313-577-9367, Wayne State University, School of Social Work, 4756 Cass Avenue, Detroit, MI 48202, USA \& Assistant Professor, Email: fl4684@skku.edu, Phone: 82-2-760-0631, Sungkyunkwan University, Humanities and Social Science Campus, Department of Social Welfare, 61505 Suseon Hall, 25-2 Sungkyunkwan-ro, Jongno-gu, Seoul, Republic of Korea; Jungup Lee, Doctoral Candidate, Email: j111ac@ my.fsu.edu, Phone: 850-644-4751, Florida State University, College of Social Work, 296 Champions Way, University Center, Building C, Tallahassee, FL 32306-2570, USA.; Dorothy L. Espelage, Edward William Gutgsell \& Jane Marr Gutgsell Endowed Professor and Hardie Scholar of Education, Email: espelage@illinois.edu; Phone: 217 766-6413, University of Illinois, Dept. of Educational Psychology, Child Development Division, 220A Education, 1310 S. Sixth Street Champaign, IL 61820, USA.; Simon C. Hunter, Senior Lecturer, Email: simon.hunter@strath.ac.uk; Phone: +44-141-548-4879, University of Strathclyde, School of Psychological Sciences and Health, 40 George Street, Glasgow G1 1QE, UK; Desmond Upton Patton, Assistant Professor, Email : dupatton@ umich.edu, phone : 734763-6582, University of Michigan, School of Social Work, 1080 S. University, Ann Arbor, MI 48109, USA ; Tyrone Rivers, Jr., Doctoral Candidate, Email : rivers4@illinois.edu; Phone: 217-333-2245, University of Illinois, Dept. of Educational Psychology, Child Development Division, 220A Education, 1310 S. Sixth Street, Champaign, IL 61820, USA 


\section{Author Note}

Correspondence concerning this article should be addressed to Jun Sung Hong, School of Social Work, Wayne State University, Detroit, MI 48202, US.

Jun Sung Hong and Jungup Lee conceived the study, wrote the Introduction, Literature Review, conducted the analyses, and wrote the Method and Results sections. Both contributed equally and are co-first authors. Dorothy L. Espelage, Simon C. Hunter, Desmond Upton Patton, and Tyrone Rivers, Jr. contributed equally and are co-second authors. Second authorship is alphabetically ordered.

Please cite this as:

Hong, J.S., Lee, J., Espelage, D.L., Hunter, S.C., Patton, D., Rivers, Jr., T. (in press). Understanding the correlates of face-to-face and cyberbullying victimization among U.S. adolescents: A social-ecological analysis. Violence and Victims.

Hong and Lee contributed equally to the manuscript. Espelage, Hunter, Patton, and Rivers, Jr. all also contributed equally and are co-second authors. Second authorship is alphabetically ordered. 


\begin{abstract}
Using a national sample of 7,533 U.S. adolescents in grades 6-10, the present study compares the social-ecological correlates of face-to-face and cyberbullying victimization. Results indicate that younger age, male sex, hours spent on social media, family SES (individual context), parental monitoring (family context), positive feelings about school, and perceived peer support in school (school context) were negatively associated with both forms of victimization. European American race, Hispanic/Latino race (individual), and family satisfaction (family context) were all significantly associated with less face-to-face victimization only, and school pressure (school context) was significantly associated with more face-to-face bullying. Peer groups accepted by parents (family context) were related to less cyberbullying victimization, and calling/texting friends was related to more cyberbullying victimization. Research and practice implications are discussed.
\end{abstract}

Keywords: adolescents; bullying; cyberbullying; social-ecological framework; victimization 
Bullying victimization constitutes a serious social concern (Espelage, 2015). Bullying is defined as unwanted aggressive behaviors perpetrated by another adolescent or group of adolescents that involves an observed or perceived power imbalance. Victims of bullying may be inflicted with physical, psychological, social, or educational harm (Gladden, Vivolo-Kantor, Hamburger, \& Lumpkin, 2014). According to the Bureau of Justice Statistics, in 2011, about $23 \%$ of public schools reported that bullying occurred in school daily and weekly, and about $28 \%$ of 12 - to 18 -year-old students nationwide reported being bullied at school. Empirical evidence suggests that the prevalence of face-to-face bullying ranges from 10 to $35 \%$ (e.g., Mishna, Cook, Saini, Wu, \& MacFadden, 2011). Cyberbullying is defined as committing a repeated assault through electronic means such as e-mails, text messages, chat rooms or instant messaging; displaying photos or videos on mobile or web; and excluding someone from social networks (Menesini \& Spiel, 2012). Approximately 5-10\% of students aged 12-18 report being cyber-bullied (Kowalski \& Limber, 2013; Robers, Kemp, Rathbun, \& Morgan, 2014). Of these students, $4 \%$ report that another student posted hurtful information on the Internet, and another 4\% report being harassed via text messages (Robers et al., 2014).

Relative to face-to-face bullying, few studies have examined correlates and antecedents of cyberbullying perpetration (Hemphill et al., 2012; Williams \& Guerra, 2007). Furthermore, fewer studies have explored the correlates of cyberbullying victimization. Moreover, some of the research comparing both types of bullying has concluded that cyberbullying has little in common with face-to-face bullying because certain correlates and antecedents are not shared by both (Hemphill et al., 2012; Law, Shapka, Domene, \& Gagne, 2012; Ortega et al., 2012). In contrast, other studies challenge this conclusion, suggesting that the correlates and antecedents of both types of bullying may be interrelated (e.g., see, Casas, Del Rey, \& Ortega-Ruiz, 2013; Dooley, 
Pyzalski, \& Cross, 2009; Low \& Espelage, 2013). The aim of the present study is to address whether cyberbullying victimization is just another form of bullying victimization or whether cyberbullying is distinct, and thus necessitates unique assessment and intervention strategies. With regards to factors which may underlie face-to-face and cyberbullying victimization, studies have recognized the importance of considering the social-ecological framework. Gaining a more thorough understanding of a social phenomenon requires an investigation of the interrelated contextual factors fostering or inhibiting bullying victimization. Both theory and research indicate that bullying victimization is an ecological phenomenon and therefore the factors influencing it need to be understood across individual, family, peer, school, and neighborhood contexts (Espelage, 2014). Indeed, the social-ecological framework has been applied to the conceptualization of bullying and victimization, and studies have identified a wide range of individual characteristics and contextual factors, the latter relating mainly to family, peer, and school (Barboza et al., 2009; Ferguson, Miguel, \& Hartley, 2009; Lopez, Perez, Ochoa, \& Ruiz, 2008). Family, peer, and school environments provide adolescents with social contexts within which they can interact with both peers and adults, thereby shaping their perceptions and attitudes toward what are considered acceptable and appropriate behaviors (Erginoz et al., 2013). Therefore, studies consistently point out that a consideration of how these different ecologies' impact bullying victimization is important.

Unlike face-to-face bullying, which begins in school, cyberbullying usually begins on home computers and on cellphones (Kowalski et al., 2005). Victims' psychosocial distress can then affect their peer relationships, interactions with teachers, and their family lives (Epstein \& Kazmierczak, 2006/2007). The social-ecological theory is an appropriate framework for examining the correlates of cyberbullying victimization because the varied contextual factors 
should all be considered when designing interventions. Applying the social-ecological framework, we compare the correlates of face-to-face victimization and cyberbullying victimization across individual, family, peer, and school contexts.

\section{Individual Context}

With regards to age, studies consistently find that face-to-face bullying increases during middle school and decreases as adolescents get older. Bullying victimization appears to be most prevalent in middle school (e.g., Espelage \& Horne, 2008; Nansel et al., 2001), and particularly during the transition from elementary to middle school (e.g., Espelage, Hong, Rao, \& Thornberg, forthcoming). By comparison, research examining age as a correlate of cyberbullying is inconclusive. Some researchers suggest that similar to face-to-face bullying, early adolescents appears to be most vulnerable to cyberbullying (see Tokunaga, 2010), while other researchers observe no significant age differences (Patchin \& Hinduja, 2008; Smith et al., 2008).

In terms of gender/sex and face-to-face victimization, past studies have produced mixed findings. Some studies report that boys are more likely to be victims of overt forms of bullying (Kyriakides, Kaloyirou, \& Lindsay, 2006; Owens, Daly, \& Slee, 2005; Vaillancourt et al., 2008) while girls are at higher risk of victimization involving relational aggression, such as spreading rumors (Kyriakides et al., 2006; Owens et al., 2005). Other studies report no such gender differences (Ball et al., 2008; Scholte, Engels, Overbeek, de Kemp, \& Haselager, 2007). A review by Dooley et al. (2009) also indicated that the gender/sex differences that are evident in face-to-face bullying are not as clear in cyberbullying. In contrast, the cyberbullying literature documents that girls are more frequently bullied than boys online (Kowalski \& Limber, 2007;

Mishna, Cook, Gadalla, Daciuk, \& Solomon, 2010; Smith et al., 2008; Wang, Iannotti, \& Nansel, 2009) and are more involved in bullying others online as well (Pornari \& Wood, 2010; Smith et 
al., 2008). Using data from 2005-2006 Health Behavior in School-aged Children, which includes a nationally representative sample of adolescents, Wang et al. (2009) found that boys were more likely to be cyberbullying perpetrators, whereas girls were more likely to be victims.

Several researchers have also found racial/ethnic differences in face-to-face victimization. Such results vary according to the specific characteristics of minority groups. For example, Spriggs, Iannotti, Nansel, and Haynie (2007) found that African American adolescents reported lower prevalence of victimization than did European American and Hispanic/Latino adolescents, while Sawyer, Bradshaw, and O’Brennan (2008) found that African American boys and girls and Asian American boys were less likely than European American adolescents to report being bullied. Other researchers (e.g., Sweeting \& West, 2001) have reported no racial/ethnic differences in bullying/victimization. For cyberbullying victimization, the majority of study participants have consisted primarily of European Americans and the racial/ethnic difference is largely unknown. However, one study (Mesch, 2009) reported that European American adolescents were less likely to be cyberbullied than adolescents from "visible minorities" and two studies have found that African American adolescents engage in cyberbullying at higher rates than adolescents of other races (Low \& Espelage, 2013; Wang, Nansel, \& Iannotti, 2011). The relations between race and ethnicity and bullying victimization is complex, and it is plausible that racial and ethnic bullying is influenced or inhibited by the characteristics and racial/ethnic composition of classroom, school, and community environments (Juvonen \& Graham, 2014; Verkuyten \& Thijs, 2002).

Hours spent on social media is positively associated with cyberbullying victimization (Hinduja \& Patchin, 2008; Holfeld \& Leadbeater, 2014; Twyman, Saylor, Taylor, \& Comeaux, 2010). Adolescents who spend a great deal of time on social media have more opportunities to be 
exposed to cyberbullying. However, this research emphasizes the importance of assessing frequency of online activity in studies on cyberbullying victimization.

Recent research also suggests that low socioeconomic status can significantly increase the risk of bullying victimization (Jansen, Veenstra, Ormel, Verhulst, \& Reijneveld, 2011; Jansen et al., 2012; Peguero \& Williams, 2013; Magklara et al., 2012; Menzer \& Torney-Purta, 2012). For instance, one Danish study reported that higher prevalence of physical and psychological symptoms of adolescents in low-income families was partially explained by high levels of exposure to bullying (Due et al., 2003). Another study investigated socioeconomic status and exposure to bullying among a sample of 11,13 , and 15 year olds $(N=162,305)$ in 35 European and North American countries. Findings suggest that adolescents of low-income reported higher prevalence of bullying victimization (Due et al., 2009). Thus, we hypothesize that younger age, male sex, European American race, and low family socio-economic status will be positively associated with face-to-face victimization, while older age, female sex, African American race, and time spent on social media will be positively associated with cyberbullying victimization.

\section{Family Context}

Family factors, such as close parent-adolescent relationships, can reduce adolescents' risk of violence outside of the home. An exploratory study of face-to-face bullying and cyberbullying by Accordino and Accordino (2011) reported that a close relationship with parents was negatively associated with both types of victimization. Specific type of parent-adolescent relationships, such as parental monitoring and support, have also been identified as salient protective factors that reduce children's exposure to violence (e.g., Kliewer et al., 2006). However, parental monitoring appears unrelated to children's face-to-face victimization 
(Stavrinides, Nikiforou, \& Georgiou, 2014). Stavrinides et al.'s (2014) findings suggest that parents' efforts to familiarize themselves with their children's friends do not decrease victimization, as victimized children frequently hide their experiences from their parents. For cyberbullying victimization, findings have been inconsistent. One study suggests that parental monitoring had a significant effect in reducing children's victimization (Sasson \& Mesch, 2014), while others have not found such an association (Low \& Espelage, 2013; Mesch, 2009). Low and Espelage's (2013) study in fact showed a positive association between parental monitoring and higher levels of cyberbullying, although face-to-face (non-physical) bullying levels were associated with lower parental monitoring. Mesch (2009) also reported that very few parental monitoring techniques were effective in reducing online victimization, and most were in fact ineffective. Similar to face-to-face victimization, children do not tell their parents and other adults about their experiences of cyberbullying, perceiving them to be oblivious to the cyberworld and to the phenomenon of cyberbullying (see Mishna et al., 2009). Thus, we hypothesize that parental monitoring will be associated with a decreased risk of face-to-face bullying but not cyberbullying victimization.

In addition to parental monitoring, adolescents' perceptions of parenting are significantly related to their experiences in bullying victimization. For instance, Dehue, Bolman, Vollink, and Pouwelse's (2012) study, which involved 67 elementary schools and 7 middle schools in the Netherlands, reported that adolescents who perceived their parents as authoritative and neglectful were at a higher risk of both face-to-face and cyberbullying victimization than those who perceived their parents as authoritative and permissive. Thus, we hypothesize that adolescents' perceptions of their family (e.g., family satisfaction) and their parents as permissive (e.g., having 
peers accepted by parents) will be associated with a decreased risk of both face-to-face and cyberbullying victimization.

\section{Friend/Peer Context}

For children, development of bullying victimization can involve influences outside the family, such as friends and peer groups. Children's friendships serve many important developmental functions, such as providing social and emotional support, and opportunities for acquiring social skills (Hartup, 1993). Friends can also serve as a protective factor against bullying victimization (Hodges, Boivin, Vitaro, \& Bukowski, 1999), with empirical evidence suggesting that a lack of friends is positively correlated with bullying victimization (Boulton, 1999; Hodges, Malone, \& Perry, 1997). Furthermore, children who are at risk for victimization because of individual characteristics (e.g., being aggressive, withdrawn, or having low social skills) are less likely to be victimized by their peers if they have friends (Fox \& Boulton, 2006; Hodges et al., 1997). This 'friendship protection hypothesis' has even been demonstrated to exist when predicting victimization across a 12-month period (Kendrick, Jutengren, \& Stattin, 2012). Much less is known about this issue in an online context, though one study indicated that having friends was negatively associated with face-to-face victimization while being unrelated to cyberbullying victimization (Wang et al., 2009). However, a more recent study (Burton, Florell, \& Wygant, 2013) found that peer attachment decreased the risk of both face-to-face and cyberbullying victimization. Thus, we hypothesize that adolescents' interactions with their friends, such as spending time with friends and calling/texting friends will be associated with reduced likelihood of bullying victimization.

\section{School Context}


School environment can also affect children's behaviors, enhancing or impairing children's academic and social development. Indeed, a positive school environment, which fosters a sense of connectedness as a result of perceived caring from teachers and peers (Wilson, 2004), has been found to be negatively related to bullying victimization (Cortes \& KochenderferLadd, 2014; Espelage, Polanin, \& Low, 2014; O’Brennan \& Furlong, 2010; Turner, Reynolds, Lee, Subasic, \& Bromhead, 2014). Turner et al. (2014) found in a sample of 492 Australian school students in grade 7 to 10 that academic and group support were the strongest predictors of change in bullying and victimization. Results from Cortes and Kochenderfer-Ladd's (2014) study, which consisted of 278 ethnically diverse 8-10 year old students, also revealed that students who perceived that teachers would take an active role in intervening in bullying situations were associated with greater willingness to report and were less likely to be victimized. However, in one large study of Canadian adolescents, school climate did not predict levels of racial victimization (Larochette, Murphy, \& Craig, 2010) suggesting that when examining specific forms of victimization we cannot immediately expect school context to be as important as individual level predictors. Thus, it is important to consider possible differential effects of school-level variables when considering face-to-face and cyberbullying, especially given the extent to which cyberbullying victimization extends beyond the school gates. Children's engagement in school and connectedness to their peers can also reduce the occurrence of cyberbullying. Thus, we hypothesize that adolescents with positive feelings about their school and perceived peer support in school will be less at risk of face-to-face bullying and cyberbullying victimization.

\section{The Present Study}


Negative social and emotional outcomes of bullying victims have been well-documented. The increasing time spent in online environments provides new avenues through which adolescents are vulnerable to bullying victimization both inside and outside of school (Raskauskas \& Stoltz, 2007). The correlates of cyberbullying in particular are important to investigate; while multiple level predictors of face-to-face bullying have been examined extensively, there appears to be a dearth of such research on cyberbullying victimization.

The present study compares correlates of face-to-face victimization and cyberbullying victimization. More specifically, we hypothesize that younger age, male, European American, and low family socio-economic status are associated with higher likelihood of face-to-face victimization. We also hypothesize that being older age, female, African American, and spending longer hours on social media will be related to higher likelihood of cyberbullying victimization. Further, we also hypothesize that family satisfaction, having friends who are accepted by parents, spending time with friends, calling/texting friends, having positive feelings about school, and perceiving peer support in school are negatively associated with face-to-face and cyberbullying victimizations. Finally, we hypothesize that parental monitoring and parent/guardian support are not significantly related to cyberbullying victimization.

\section{Method}

\section{Data and Sample}

The present study utilized data from the 2005-2006 Health Behavior in School-aged Children (HBSC) study in the United States. HBSC is a World Health Organization schoolbased, cross-national study, which consists of standardized survey items and methods across 44 countries. Anonymous, self-report questionnaires were distributed in classrooms and completed by a nationally representative sample of $6^{\text {th }}$ to $10^{\text {th }}$ graders. The final sample consisted of 7,533 
adolescents in grades 6-10 in public and private schools in the U.S. The weighted sample was 48.5\% male and 51.5\% female and included 51\% European American, 20\% African American, and 27\% Hispanic/Latino. The mean age of the sample was $14.33(\mathrm{SD}=1.38)$ years. $<<$ Insert Table 1, about here >>

\section{Measures}

Face-to-face and cyberbullying victimizations. The outcome variables for the present study are face-to-face and cyberbullying victimization, which were based on the revised Olweus Bully/Victim Questionnaire (Solberg \& Olweus, 2003). Face-to-face victimization was measured by six items, which include, "I was called mean names, made fun of, or teased in a hurtful way", "Other students left me out of things on purpose, excluded me from their group of friends, or completely ignored me”, "I was hit, kicked, pushed, shoved around, or locked indoors", “Other students told lies or spread false rumors about me and tried to make others dislike me", "I was bullied with mean names and comments about my race or color", and "I was bullied with mean names and comments about my religion" $(\alpha=.83)$. Cyberbullying victimization was measured with two items, "I was bullied using a computer or e-mail messages or pictures" and "I was bullied using a cell phone" $(\alpha=.79)$. Responses categories for both face-to-face and cyberbullying victimizations were $1=$ never, $2=$ only once or twice, $3=2$ or 3 times a month, 4 $=$ about once a week, and $5=$ several times a week.

Individual context. Predictor variables at the individual level include age, gender/sex, race/ethnicity, hours spent on social media, and family socio-economic status. Gender/sex ("Are you a boy or a girl?") involves a response category, male or female. Grade in school ("What grade are you in?") includes a response category ranging from $1=$ grade 6 to $5=$ grade 10 . Racelethnicity ("What do you consider your race/ethnicity to be?”) was collapsed into three 
categories: European American, African American, and Hispanic/Latino. Hours spent on social media was measured with two items, "About how many hours a day do you usually use a computer for chatting online, internet, emailing, etc. in your free time on weekdays?" and "About how many hours a day do you usually use a computer for chatting online, internet, emailing, etc. in your free time on weekends?" These were collapsed into one category, with responses ranging from $1=$ never at all to $9=$ about 7 or more hours a day $(\alpha=.87)$. Family socio-economic status includes one item, "How well off do you think your family is?" with a response categories ranging from $1=$ very well off to $5=$ not at all well off.

Family context. Included here were parental monitoring, parent/guardian support, family satisfaction, peer groups accepted by parents. Parental monitoring was measured with eight items, "(Mother knows) who your friends are", "(Mother knows) where you are after school", “(Mother knows) where you go at night", “(Mother knows) what you do with free time”, "(Father knows) who your friends are", "(Father knows) where you are after school”, "(Father knows) where you go at night”, and “(Father knows) what you do with free time." Response options ranged from 1 = knows a lot, $2=$ knows a little, 3 = doesn't know anything, and $4=$ don't have/see parent, which were recoded as $1=$ not at all to $3=\mathrm{a} \operatorname{lot}(\alpha=.84)$.

Parent/guardian support was measured with three items, "Helps me as much as I need", "Is loving", and "Understands my problems and worries" with response categories ranging from $1=$ almost always to $3=$ almost never, which were recoded as $1=$ almost never to $3=$ almost always $(\alpha=.80)$. Family satisfaction was measured with one item, "In general, how satisfied are you with the relationships in your family?" Response categories ranged from $0=$ we have very bad relationships in our family to $10=$ we have very good relationships in our family. Peer groups accepted by friends was measured with one item, "Your group of friends is well accepted 
by your parents" with response categories ranging from $1=$ almost always to $4=$ they have not met your group of friends and was recoded as $1=$ never, $2=$ sometimes, and $3=$ almost always .

Friend/peer context. Friend/peer context variables include three items: "How many days a week do you usually spend time with friends right after school?" ( $0=0$ days; $6=6$ day), "How many evenings per week do you usually spend out with friends?" ( $0=0$ evenings; $7=7$ evenings), and "How often do you talk to your friend(s) on the phone or send them text messages or have contact through the internet?" ( $1=$ rarely/never; $5=$ every day). The first two items were collapsed into one category (i.e., "spending days/nights per week with friends) ( $\alpha=.72$ ).

School context. Variables at the school context include feelings about school, perceived peer support in school, and schoolwork pressure. Feelings about school was measured with one item, "How do you feel about school at present?" with response categories ranging from $1=\mathrm{I}$ like it a lot to $4=\mathrm{I}$ don't like it at all. This was recorded as $1=\mathrm{I}$ don't like it at all to $4=\mathrm{I}$ like it a lot. Perceived peer support in school was measured with three items, "The students in my class(es) enjoy being together", "Most of the students in my class(es) are kind and helpful," and "Other students accept me as I am". Response categories ranged from $1=$ strongly agree to $5=$ strongly disagree, which was reverse coded as $1=$ strongly disagree to $5=$ strongly agree $(\alpha=$ .71). Schoolwork pressure was measured with one item, "How pressured do you feel by the schoolwork you have to do?" with response categories ranging from $1=$ not at all to $4=$ a lot.

\section{Analyses}

We utilized all statistical analyses with sample weights to provide measures that were representative of the $6^{\text {th }}-10^{\text {th }}$ graders and conducted them using STATA software version 11.0. Statistical analyses occurred in several phases. We first estimated descriptive analyses to calculate variable distributions in multivariate analyses and conducted bivariate correlations 
between all the potential variables. In the second phase, principal factor analyses (or principal axis factoring methods) with varimax rotation of composite subscales were conducted to investigate whether the variables would be categorized by appropriate factors. Based on existing theoretical and empirical studies in the social-ecological approach, and based on the hypotheses, the variables may be grouped into categories representing family, friend/peer, and school. To address the first two hypotheses, we include individual level factors, such as age, gender/sex, race/ethnicity, family socio-economic status, and hours on social media in Model 1. To address the hypothesis that parental monitoring and parent/guardian support will not be associated with cyberbullying victimization, we added family level factors, such as parental monitoring, family satisfaction, and parent/guardian in Model 2. And to address the hypothesis that individual, family, friend/peer, and school level factors will be associated with both types of victimization, we added these variables in Model 3 and Model 4. In the final phase, we performed four-step ordinary least squares (OLS) regression models to examine the association between variables of social-ecological contexts and two outcome variables (face-to-face and cyberbullying victimizations), respectively. These regressions were conducted in this manner to evaluate the unique effects of a wider social-ecological context after controlling for more proximal contextual effects; thus individual variables were entered in Model 1, followed by family factors in Model 2, friend/peer factors in Model 3, and finally, school factors in Model 4.

\section{Results}

\section{Bivariate Correlations}

Table 2 displays the results of the bivariate correlations between all predictor variables in the analyses. Both face-to-face and cyberbullying victimizations were significantly correlated with age, race/ethnicity (European American and African American), hours spent on social 
media, and Family SES. However, only cyberbullying victimization was associated with gender/sex and Hispanic/Latino ethnicity. Parental monitoring, parental/guardian support, family satisfaction, and peer groups accepted by parents were negatively correlated with both face-toface and cyberbullying victimizations. Time spent with friends was negatively correlated with face-to-face victimization, but positively with cyberbullying victimization. Calling/texting friends was negatively correlated with face-to-face victimization, but not correlated with cyberbullying victimization. Both face-to-face and cyberbullying victimizations were negatively associated with two school related variables including feelings about school and perceived peer support in school, but positively associated with schoolwork pressure.

$<<$ Insert Table 2, about here>>

\section{Factor Structures Related to the Social-Ecological Framework}

Principal axis factoring method was performed to determine underlying dimensions to create composite measures of our subscales (see Table 3). The initial eigenvalues of the first three factors were above 1 (2.76 for family, 1.33 for friend/peer, and 1.05 for school). The three factors explained $30.7 \%, 14.8 \%$, and $11.7 \%$ of the variance, respectively and in total $57.1 \%$ of the variance explained. The factor loading from principal axis factoring with varimax rotation of composite subscales reported all the items have .30 or above of factor loading with satisfactory Cronbach's alphas (see Table 3).

We labeled the following three factors according to the items in each factor: the family factor comprised parental monitoring, parent/guardian support, family satisfaction, and peer groups accepted by parents; the friend/peer factor included time spent with friends and calling/texting friends; and the school factor comprised feelings about school, perceived peer support in school, and schoolwork pressure. 
$<<$ Insert Table 3, about here >>

\section{The Social-Ecological Contexts and Face-to-Face and Cyberbullying Victimizations}

Ordinary least squares (OLS) regression models were created to test the research hypotheses regarding the effects of social-ecological contextual variables on face-to-face and cyberbullying victimizations. The four models were specified as follows: Model 1 included age, gender/sex, race/ethnicity, hours spent on social media, and family SES as the individual variables and face-to-face and cyberbullying victimizations as the dependent variables. Model 2 included the same variables as Model 1 with the four family variables - parental monitoring, parent/guardian support, family satisfaction, and peer groups accepted by parents. Model 3 included the same variables as Model 2 with the two friend/peer variables - time spent with friends and calling/texting friends. Model 4 included the same variables as Model 3 with the three school variables - feelings about school, perceived peer support in school, and schoolwork pressure. The results for the association between predictor variables and face-to-face victimization are presented in Table 4, and those for the association between predictor variables and cyberbullying victimization are presented in Table 5.

Individual factors. In Model 1 of face-to-face victimization, our results indicated that younger age, male, non-European American, longer hours spent on social media, and lower family SES were correlated with higher likelihood of face-to-face victimization. Age predicted reduced likelihood of face-to-face victimization $(\beta=-.13, p<.001)$. Female and European American participants were less likely than male and non-European Americans to experience face-to-face victimization $(\beta=-.03, \mathrm{p}<.01 ; \beta=-.04, \mathrm{p}<.05)$. Hours on social media was correlated with an increased likelihood of face-to-face victimization, which indicated adolescents 
who spent more hours on social media, experienced more face-to-face victimization $(\beta=.07, p<$ $.001)$. Family SES was negatively related to face-to-face victimization $(\beta=-.10, p<.001)$.

In Model 1 of cyberbullying victimization, younger age, male, longer hours spent on social media, and lower family SES were found to be significantly associated with higher likelihood of cyberbullying victimization. More specifically, adolescents who were younger, male, spent longer hours on social media, and those with lower family SES were more likely to have higher likelihood of cyberbullying victimization. Unlike the negative association between European American race and face-to-face victimization, however, African American race was positively related to cyberbullying victimization $(\beta=.04, \mathrm{p}<.01)$. The standardized effects of those were -.04 for age, -.03 for female, .04 for African American race, .08 for hours spent on social media, and -.03 for family SES.

Family factors. In Model 2 of face-to-face victimization, we found that parental monitoring $(\beta=-.05, p<.01)$, family satisfaction $(\beta=-.12, p<.001)$, and peer groups accepted by parents $(\beta=-.04, p<.01)$ were significantly, negatively associated with face-to-face victimization, but parent/guardian support was not. More specifically, adolescents who were monitored from their parents, were satisfied with family relationships, and had their group of friends well accepted by their parents were less likely to experience face-to-face victimization. The effects of the individual variables in Model 1 still remained in Model 2.

In Model 2 of cyberbullying victimization, while parental monitoring $(\beta=-.06, p<.001)$ and peer groups accepted by parents $(\beta=-.03, p<.05)$ were negatively related to cyberbullying victimization, parent/guardian support and family satisfaction were not. Among the significant individual variables in Model 1, the impacts of age, gender/sex, and hours spent on social media still persisted in Model 2, but not African American race and family SES. 
Friend/peer factors. In Model 3 of face-to-face victimization, both time spent with friends $(\beta=-.03, p<.05)$ and calling/texting friends $(\beta=-.04 ; p<.01)$ had negative associations with face-to-face victimization. In other words, students who spent more time with their friends after school and talked with them on the phone, sent them text massages, or contacted to them through the internet more often were less likely to have the likelihood of face-to-face victimization.

The impacts of the individual variables and family factors in Model 2 still remained in Model 3. In addition, Hispanic/Latino ethnicity was a significant individual variable, which indicated that Hispanic/Latino adolescents was less likely than non-Hispanic/Latino to have the likelihood of face-to-face victimization $(\beta=-.03, p<.05)$. While time spent with friends and calling/texting friends were significant associated with face-to-face victimization, those were not significant with cyberbullying victimization. The effects of the individual variables and family factors in Model 2 still remained significant in Model 3 of cyberbullying victimization.

School factors. In Model 4 of face-to-face victimization, we found that feelings about $\operatorname{school}(\beta=-.03, p<.05)$ and perceived peer support in school $(\beta=-.19, p<.001)$ were negatively related to face-to-face victimization, but schoolwork pressure was positively related $(\beta=.06, p<.001)$. All of the significant variables in Model 3 remained significant in Model 4, with the exception family SES and the three family variables.

In Model 4 of cyberbullying victimization, while feelings about school $(\beta=-.06, p<$ $.001)$ and perceived peer support in school $(\beta=-.06, p<.001)$ were negatively related to cyberbullying victimization, schoolwork pressure was not significant. All of the significant variables in Model 3 remained significant in Model 4. Unlike the results in Model 3, calling/texting friends $(\beta=.03, p<.05)$ was positively related to cyberbullying victimization in 
Model 4. Adolescents who frequently talked with their friends on the phone, sent them text messages, or contacted to them through the internet were more likely to be bullied in cyberspace. <<Insert Tables 4, about here〉>

\section{Discussion}

The present study is the first to situate our understanding of the correlates of both face-toface and cyber-bullying victimization within the social-ecological framework. Our results indicate that there are important similarities and differences across these contexts in their association with victimization and that those relationships are similar or different depending upon whether victimization is face-to-face or taking place in cyberspace.

Supporting previous research (Espelage \& Horne, 2008; Nansel et al., 2001; Tokunaga, 2010) and our hypothesis, we found lower levels of face-to-face victimization as our sample got older. Contrary to our hypothesis, however, age was also negatively associated with cyberbullying victimization. We should note that younger adolescents are also more likely to divulge bullying victimization than older adolescents (Beran \& Tutty, 2002) so it is possible that such age trends are artefacts of young people's willingness to report victimization. Our results partially support our hypothesis that boys would experience more face-to-face victimization, supporting other literature (Espelage, Bosworth, \& Simon, 2000; Varjas, Henrich, \& Meyers, 2009). Surprisingly, our finding that girls were more frequently victims of cyberbullying than boys is contradictory to our hypothesis and to another study also using the HBSC data (Wang et al., (2009). Although past studies suggest that African American adolescents are involved in more face-to-face bullying perpetration but less victimization (e.g., Wang et al., 2009), African American sample in our study were more likely to experience victimization via cyberspace, which supports our hypothesis. This finding is in agreement with Nansel et al.'s (2001) study, 
which found that African American adolescents report higher rate of face-to-face victimization than their Hispanic/Latino and European American peers. In contrast, European American adolescents in our sample were least likely to experience face-to-face victimization, which did not support our hypothesis. Moreover, we found that adolescents who spent longer using social media were at increased risk of cyberbullying victimization, which is congruent with our hypothesis. Time spent on social media can expose adolescents to bullying via cyberspace. Furthermore, adolescents of lower family SES reported higher risk of cyberbullying victimization rather than face-to-face bullying victimization, which was contrary to our hypothesis. This finding might indicate that these adolescents are likely to reside in a neighborhood where they are frequently exposed to violence and are victimized not only offline but also online (see Patton, Eschmann, \& Butler, 2013).

Concurrent with our hypothesis and the idea that parents are important contributors to the development of their children's peer relations (Accordino \& Accordino, 2011; Dehue et al., 2012), we also found that adolescents who report parental monitoring and peer groups accepted by parents are at a lower risk of face-to-face bullying. Contrary to our proposed hypothesis, our findings indicate that parental monitoring is negatively associated with cyberbullying victimization. This finding may reflect the importance of parental awareness of adolescents' relations with their peers, which can lead to parents' involvement in situations where adolescents are bullied by their peers. However, as our finding suggests, adolescents who reported family satisfaction are less likely to be victimized face-to-face, but family satisfaction was not related to cyberbullying victimization, which partially supports our hypothesis. It is conceivable that despite adolescents' satisfaction with their family, those with access to social media may still be at risk of cyberbullying victimization. 
Our results also demonstrate that adolescents who spent time with their friends and those who call/text their friends are at a decreased risk of face-to-face victimization. This is consistent with our hypothesis and with the "friendship protection hypothesis" which posits that friendships provide a protective buffer against negative factors, such as victimization (Bukowski, Hoza, \& Boivin, 1994). However, for cyberbullying victimization, this was not the case, which was incompatible with our hypothesis and other findings (e.g., Burton et al., 2013). It is plausible that adolescents discuss cyberbullying victimization less often with their friends and gain less support when such experiences occur, although our data do not allow for investigating such a possibility.

As expected, adolescents who reported positive feelings about their school and those who perceived receiving peer support in school are also less at risk of face-to-face and cyberbullying victimizations, which are consistent with our hypothesis and study findings (Hodges et al., 1997; Spriggs et al., 2007). These adolescents may feel good about themselves and the institutions in which they function, and as a result, they may engage in school more and display fewer behavior problems, mitigating their risk of peer rejection and peer victimization (Hodges et al., 1999). On the contrary, as this study demonstrates, feeling pressured from school work increases adolescents' risk of face-to-face victimization. It is possible that stress in school is associated with an increased risk of victimization. Adolescents who experience stress may alienate themselves from their peers and school, which can increase their risk of victimization (see Natvig, Albrektsen, \& Qvarnstrom, 2001).

\section{Limitations}

Although a contribution to the literature on the overlap between face-to-face bullying and cyberbullying experiences among youth, this study is limited in several respects. First, this study is cross-sectional, which limits causal claims and temporal order of effects. A longitudinal design 
is needed to investigate the order of the effects of the various social-ecological factors with the development of face-to-face and cyberbullying victimization over a period of time. Second, the study utilized the 2005-2006 Health Behavior in School-aged Children data, which are somewhat dated, but still relevant. Rapid changes in technology may have occurred since the data have been collected. As a result, our findings may not accurately reflect adolescents' use of social media in the current form. Notwithstanding this limitation, the present study can still build on extant literature, as factors that are still relevant to the present-day have been examined. Future research might build on the present findings by utilizing the 2005-2006 dataset as a baseline to be compared and contrasted over time. Third, the study relied only on self-report measures, and did not include data from teachers, peers, or parents. For example, studies that incorporate multi-informants are needed to understand how self-reported victimization converge with the perceptions of teachers, who are known to vary in their level of intervention to help youth who are victimized face-to-face (Espelage, 2014). Fourth, the prevalence of face-to-face bullying appears to be much higher than cyberbullying. It is possible that some of the differences in the outcomes are attributed to differences in the prevalence of face-to-face bullying and cyberbullying. Fifth, although statistically significant, the findings are small in magnitude, given betas of less than .10 and often less than .05 . As such, this may reflect inflation of Type I error associated with large sample. Sixth, there are also limitations in the items worth noting. Several constructs were assessed with single-item indicators, limiting their reliability and thus their construct validity, which could explain the low amount of variance explained by the models. Also, family SES items appear to be problematic in that youths' responses are based on their own biases about what "well off is," and potentially based on comparisons to others in their school or neighborhood, which vary considerably among respondents given the national data. 
And the parental monitoring scale does not take into account youth who do not reside with their parents. Finally, a significant amount of variance remained unexplained in the models, suggesting that future studies should include a broader set of correlates.

\section{Implications for Research}

These limitations aside, results from the present study highlight the importance of investigating the correlates of both face-to-face and cyberbullying victimization. Future studies might further explore the correlates with additional measures such as occurrence of cyberbullying victimization in other social media (e.g., Instant Messaging, Facebook, MySpace, and Twitter) as well as other relevant correlates not included in this study, such as perceived support from teachers. Moreover, as our results show, African American adolescents reported higher risk of cyberbullying victimization than their European American and Hispanic/Latino counterparts. Researchers might extend this finding by investigating culturally relevant factors that may influence or inhibit racial and ethnic minority adolescents' involvement in cyberbullying, such as perceived discrimination. Although numerous studies on the experiences in bullying among racial and ethnic minority adolescents have emerged over the years (Fitzpatrick, Dulin, \& Piko, 2007; Storch, Nock, Masia-Warner, Barlas, 2003), there remains a gap in research that focusses specifically on racial and ethnic minority adolescents' experiences of cyberbullying.

Our study also suggests that low family SES is a significant risk factor of cyberbullying victimization. As research has shown, adolescents of low SES have less access to resources, which can increase their odds of being victimized by their peers, both online and offline. Future research might consider exploring whether the digital divide might play a role in terms of race/ethnicity, socio-economic status, and cyberbullying victimization. Studies might also 
investigate possible mediators that elucidate the association between low family SES and bullying victimization, such as socio-emotional problems. More importantly, research also needs to identify protective factors, which can buffer the effect of low SES on adolescents' peer relationships. For instance, future studies might test potential moderators, such as parent/guardian support, family satisfaction, and perceived peer support in school, to better understand when, and under what conditions the association between low SES and bullying victimization is likely or less likely to occur.

It is also imperative that future research examine neighborhood factors associated with face-to-face and cyberbullying victimizations. Although scant, extant research suggests that community/neighborhood level factors, such as disorganization, economic deprivation, chronic violence, and presence of gang can increase adolescents' vulnerability to victimization (Espelage \& De La Rue, 2011; Low \& Espelage, 2014), both offline and online. Most recent research also suggest that some adolescents utilize social media platforms in urban communities to instigate bullying online (see Patton et al., 2013; Patton et al., 2014), which can contribute to cyberbullying victimization. In sum, the present study highlights a critical need for additional research to examine other factors that may increase the risk of face-to-face and cyberbullying victimization, which can contribute to the development of effective practice and policy.

\section{Implications for Practice}

Findings from the current study also have major implications for practice. Middle school youth reported greater face-to-face bullying and cyberbullying than high school youth. Thus, practitioners working with victims of bullying in middle schools (e.g., school psychologists, counselors, and social workers) might assess students' social activities, both offline and online, and develop and implement a bully prevention training for students throughout their schooling as 
they move through grade levels. Moreover, because males are more prone to both face-to-face bullying and cyberbullying than females, practitioners need to implement strategies that consider gender relations as a priority for prevention and intervention in bullying situations (Silva, Pereira, Mendonca, Nunes, \& de Oliveira, 2013). As our findings also indicate, adolescents who spent more hours on social media were at an increased risk of both face-to-face bullying and cyberbullying. Thus, it is imperative that practitioners work with youth to help them to responsibly navigate and use social media platforms. Practitioners need to also communicate closely with youth, parents, and teachers about the warning signs of face-to-face bullying and cyberbullying victimization. For example, a child's reluctance to use social media, a change in his or her behavior (e.g., school avoidance), and diminished academic performance are signs that youth might be experiencing bullying. Practitioners should advocate for the development and implementation of internet safety policies and computer use rules and protocols in school (Feinberg \& Robey, 2009).

Our findings also suggest that parental monitoring is associated with a decreased risk of face-to-face bullying and cyberbullying. Indeed, parental monitoring of adolescents, which involves tracking their behavior and peer relations, as well as being aware of their whereabouts at all times, is critical for adolescents (Dishion, Kavanagh, Schneiger, Nelson, \& Kaufman, 2002; Dishion \& Stormshak, 2007). However, peer relationships during adolescence become more diffuse, and parents are less able to monitor their adolescent children's friendships and peer communications (Higgins \& Persons, 1983). Practitioners working with parents of children who are bullied might encourage closer communications between home and school regarding their children's academic and school behavior and their peer relations, both offline and online. As 
studies have pointed out, parent-school collaborations are associated with greater positive youth outcomes (Cox, 2005; Sheridan, Warnes, \& Dowd, 2004).

And finally, our study found that adolescents' perceptions of their school environment are related to both face-to-face bullying and cyberbullying victimization. It is not surprising that adolescents who perceive their school to be a positive place and those who report feeling supported by their peers are less likely to be victimized by their peers via face-to-face and cyberspace. Practitioners and school administrators need to be work together to develop schoolwide bullying prevention and intervention efforts that target individuals involved in bullying, and which foster a safe school environment (Espelage et al., 2014). Such efforts might include developing a code of conduct that reinforces values of caring, empathy, respect, fairness, and personal responsibility; enforcing consequences of bullying consistently; establishing nonthreatening ways for students to report bullying (e.g., ensuring confidentiality); and training educators and school personnel in identifying and responding to both face-to-face bullying and cyberbullying (Espelage et al., 2014; Feinberg, 2003).

The importance of understanding the interrelations among individual, families, peer, and school level factors in bully prevention and intervention efforts have gained considerable empirical support over the years (Swearer, Espelage, Vaillancourt, \& Hymel, 2010). Indeed, the current study highlights a critical need for additional research to examine multiple factors that may increase or decrease the risk of both face-to-face and cyberbullying, which can contribute to the development of effective prevention strategies. 


\section{References}

Accordino, D. B., \& Accordino, M. P. (2011). An exploratory study of face-to-face and cyberbullying in sixth grade students. American Secondary Education, 40, 14-30.

Ball, H. A., Arseneault, L., Taylor, A., Maughan, B., Caspi, A., \& Moffitt, T. E. (2008). Genetic and environmental influences on victims, bullies and bully-victims in childhood. Journal of Child Psychology and Psychiatry, 49, 104-112. doi: 10.1111/j.14697610.2007.01821.x

Barboza, G. E., Schiamberg, L. B., Oehmke, J., Korzeniewski, S. J., Post, L. A., \& Heraux, C. G. (2009). Individual characteristics and the multiple contexts of adolescent bullying: An ecological perspective. Journal of Youth and Adolescence, 38, 101-121. doi: 10.1007/s10964-008-9271-1

Beran, T. N., \& Tutty, L. (2002). Children's reports of bullying and safety at school. Canadian Journal of School Psychology, 17, 1-14. doi: 10.1177/082957350201700201

Boulton, M. J. (1999). Concurrent and longitudinal relations between children's playground behavior and social preference, victimization, and bullying. Child Development, 70, 944954. doi: $10.1111 / 1467-8624.00068$

Bukowski, W. M., Hoza, B., \& Boivin, M. (1994).Measuring friendship quality during pre- and early adolescence: The development and psychometric properties of the Friendship Qualities Scale. Journal of Social and Personal Relationships, 11, 471-484. doi: $10.1177 / 0265407594113011$

Burton, K. A., Florell, D., \& Wygant, D. B. (2013). The role of peer attachment and normative beliefs about aggression on traditional bullying and cyberbullying. Psychology in the Schools, 50, 103-115. doi: 10.1002/pits.21663 
Casas, J. A., Del Rey, R., \& Ortega-Ruiz, R. (2013). Bullying and cyberbullying: Convergent and divergent predictor variables. Computers in Human Behavior, 29, 580-587. doi: 10.1016/j.chb.2012.11.015

Cortes, K., \& Kochenderfer-Ladd, B. (2014). To tell or not to tell: What influences children's decisions to report bullying to their teachers? School Psychology Quarterly, 29, 336-348. doi: $10.1037 /$ spq0000078

Cox, D. D. (2005). Evidence-based interventions using home-school collaboration. School Psychology Quarterly, 20, 473-497. doi: http://dx.doi.org/10.1521/scpg.2005.20.4.473

Dehue, F., Bolman, C., Vollink, T., \& Pouwelse, M. (2012). Cyberbullying and traditional bullying in relation to adolescents' perception of parenting. Journal of CyberTherapy \& Rehabilitation, 5, 25-34.

Dishion, T. J., Kavanagh, K., Schneigher, A., Nelson, S. E., \& Kaufman, N. (2002). Preventing early adolescent substance use: A family-centered strategy for the public middle-school ecology. In R. L., Spoth, K. Kavanagh, \& T. J. Dishion (eds.), Universal family-centered prevention strategies: Current findings and critical issues for public health impact [Special issue]. Prevention Science, 3, 191-201. doi: 10.1023/A:1019994500301

Dishion, T. J., \& Stormshak, E. A. (2007). Intervening in children's lives: An ecological, familycentered approach to mental health care. Washington, DC: American Psychological Association.

Dooley, J. J., Pyzalski, J., \& Cross, D. (2009). Cyberbullying versus face-to-face bullying: A theoretical and conceptual review. Journal of Psychology, 217, 182-188. doi: 10.1027/004-3409.217.4.182 
Epstein, A., \& Kazmierczak, J. (2006/2007). Cyber bullying: What teachers, social workers, and administrators should know. Illinois Child Welfare, 3, 41-51.

Erginoz, E., Alikasifoglu, M., Ercan, O., Uysal, O., Alp, Z., Tanyildiz, G. O...\& Kaymak, D. A. (2013). The role of parental, school, and peer factors in adolescent bullying involvement: Results from the Turkish HBSC 2005/2006 Study. Asia-Pacific Journal of Public Health. doi: $10.1177 / 1010539512473144$

Espelage, D. L. (2014). Ecological theory: Preventing youth bullying, aggression, and victimization. Theory into Practice, 53, 257-264. doi: 10.1080/00405841.2014.947216.

Espelage, D. L. (2015). Emerging issues in school bullying research \& prevention science. In E. T. Emmer, \& E. Sabornie (Eds.), Handbook of classroom management: Research, practice, and contemporary issues. New York: Taylor \& Francis.

Espelage, D. L., Bosworth, K., \& Simon, T. R. (2000). Examining the social context of bullying behaviors in early adolescence. Journal of Counseling \& Development, 78, 326-333. doi: 10.1002/j.1556-6676.2000tb01914.x

Espelage, D. L., \& De La Rue, L. (2011). Getting serious about community-based approaches to youth violence prevention. Progress in Community Health Partnerships: Research, Education, and Action, 5, 3-5. doi: 10.1353/cpr.2011.0006

Espelage, D. L., Hong, J. S., Rao, M. A., \& Thornberg, R. (in press). Understanding ecological factors associated with bullying across the elementary to middle school transition in the United States. Violence and Victims.

Espelage, D., \& Horne, A. (2008). School violence and bullying prevention: From research based explanations to empirically based solutions. In S. Brown \& R. Lent (Eds.), 
Handbook of counseling psychology ( $4^{\text {th }}$ ed., pp. 588-606). Hoboken, NJ: John Wiley and Sons.

Espelage, D. L., Polanin, J. R., \& Low, S. K. (2014). Teacher and staff perceptions of school environment as predictors of student aggression, victimization, and willingness to intervene in bullying situations. School Psychology Quarterly, 29, 287-305. doi: $10.1037 / \mathrm{spq} 0000072$

Farrington, D. P. (1991). Childhood aggression and adult violence: Early precursors and later-life outcomes. In D. J. Pepler \& K. H. Rubin (Eds.), The development and treatment of childhood aggression (pp. 5-29). Hillsdale, NJ: Erlbaum.

Feinberg, T. (2003). Bullying prevention and intervention. Principal Leadership, 4, 10-14.

Feinberg, T., \& Robey, N. (2009). Cyberbullying: Intervention and prevention strategies. National Association of School Psychologists, 38, 1-5.

Ferguson, C. J., Miguel, C. S., \& Hartley, R. D. (2009). A multivariate analyses of youth violence and aggression: The influence of family, peers, depression and media violence. Journal of Pediatrics, 155, 904-908. doi: 10.1016/j.jpeds.2009.06.021

Fitzpatrick, K. M., Dulin, A. J., \& Piko, B. F. (2007). Not just pushing and shoving: School bullying among African American adolescents. Journal of School Health, 77, 16-22. doi: 10.1111/j.174601561.2007.00157.x

Fox, C. L., \& Boulton, M. J. (2006). Friendship as a moderator of the relationship between social skills problems and peer victimisation. Aggressive Behavior, 32, 110-121. doi: 10.1002/ab.20114

Gladden, R. M., Vivolo-Kantor, A. M., Hamburger, M. E., \& Lumpkin, C. D. (2014). Bullying surveillance among youths: Uniform definitions for public health and recommended data 
elements, version 1.0. Atlanta, GA: National Center for Injury Prevention and Control, Centers for Disease Control and Prevention and U.S. Department of Education.

Hartup, W. W. (1993). Adolescents and their friends. In B. Laursen (Ed.), Close friendships in adolescence (pp. 3-22). San Francisco: Jossey-Bass.

Hemphill, S. A., Kotevski, A., Tollit, M., Smith, R., Herrenkohl, T. I., Toumbourou, J. W., \& Catalano, R. F. (2012). Longitudinal predictors of cyber and traditional bullying perpetration in Australian secondary school students. Journal of Adolescent Health, 51, 59-65. doi: 10.1016/j.jadohealth.2011.11.019

Higgins, E. T., \& Parsons, J. E. (1983). Social cognition and the social life of the child: Stages as subcultures. In E. T. Higgins, D. W. Ruble, \& W. W. Hartup (eds.), Social cognition and social behavior: Developmental issues (pp. 15-62). New York: Cambridge University Press.

Hinduja, S., \& Patchin, J. W. (2008). Cyberbullying: An exploratory analysis of factors related to offending and victimization. Deviant Behavior, 29, 129-156. doi:

$10.1080 / 01639620701457816$

Hodges, E. V. E., Boivin, M., Vitaro, F., \& Bukowski, W. M. (1999). The power of friendship: Protection against an escalating cycle of victimization. Developmental Psychology, 35, 94-101. doi: 10.1037/0012-1649.35.1.94

Hodges, E. V. E., Malone, M. J., \& Perry, D. G. (1997). Individual risk and social risk as determinants of victimization in the peer group. Developmental Psychology, 33, 10321039. doi: 10.1037/0012-1649.33.6.1032 
Holfeld, B., \& Leadbeater, B. J. (2014). The nature and frequency of cyber bullying behaviors and victimization experiences in young Canadian children. Canadian Journal of School Psychology. doi: 10.1177/0829573514556853.

Jansen, D. E. M. C., Veenstra, R. Ormel, J., Verhulst, F. C., \& Reijneveld, S. A. (2011). Early risk factors for being a bully, victim, or bully/victim in late elementary and early secondary education. The longitudinal TRAILS study. BMC Public Health 11, 440. doi: $10.1186 / 1471-2458-11-440$

Jansen, P. W., Verlinden, M., Dommisse-van Berkel, A., Mieloo, C., van der Ende, J., Veenstra, R., ...Tiemeier, H. (2012). Prevalence of bullying and victimization in early elementary school: Do family and school neighbourhood socioeconomic status matter? BMC Public Health, 12, 494. doi: 10.1186/1471-2458-12-494

Juvonen, J., \& Graham, S. (2014). Bullying in schools: The power of bullies and the plight of victims. Annual Review of Psychology, 65, 159-185. doi: 10.1146/annurev-psych010213-115030

Kendrick, K., Jutengren, G., \& Stattin, H. (2012). The protective role of supportive friends against bullying perpetration and victimization. Journal of Adolescence, 35, 1069-1080. doi: 10.1016/j.adolescence.2012.02.014

Kliewer, W., Murrelle, L., Prom, E., Ramirez, M., Obando, P., Sandi, L., \& Karenkeris, M. D. K. (2006). Violence exposure and drug use in Central American youth: Family cohesion and parental monitoring as protective factors. Journal of Research on Adolescence, 16, 455478. doi: 10.1111/j.1532-7795.2006.00502.x

Kowalski, R. M., \& Limber, S. P. (2007). Electronic bullying among middle school students. Journal of Adolescent Health, 41, S22-S30. doi: 10.1016/j.jadohealth.2007.08.017 
Kowalski, R. M., \& Limber, S. P. (2013). Psychological, physical, and academic correlates of cyberbullying and traditional bullying. Journal of Adolescent Health, 53, S13-S20. doi: 10.1016/j.jadohealth.2012.09.018

Kyriakides, L., Kaloyirou, C., \& Lindsay, G. (2006). An analysis of the Revised Olweus Bully/Victim Questionnaire using the Rasch measurement model. British Journal of Educational Psychology, 76, 781-801. doi: 10.1348/000709905X53499

Larochette, A., Murphy, A. N., \& Craig, W. M. (2010). Racial bullying and victimization in Canadian school-aged children: Individual and school level effects. School Psychology International, 31, 389-408. doi: 10.1177/0143034310377150

Law, D. M., Shapka, J. D., Domene, J. F., \& Gagne, M. H. (2012). Are cyberbullies really bullies? An investigation of reactive and proactive online aggression. Computers in Human Behavior, 28, 664-672. doi: 10.1016/j.chb.2011.11.013.

Lopez, E. E., Perez, S. M., Ochoa, G. M., \& Ruiz, D. M. (2008). Adolescent aggression: Effects of gender and family and school environments. Journal of Adolescence, 31, 433-450. doi: 10.1016/j.adolescence.2007.09.007

Low, S., \& Espelage, D. (2013). Differentiating cyberbullying perpetration from non-physical bullying: Commonalities across race, individual, and family predictors. Psychology of Violence, 3, 39-52. doi: 10.1037/a0030308

Low, S., \& Espelage, D. (2014). Conduits from community violence exposure to peer aggression and victimization: Contributions of parental monitoring, impulsivity, and deviancy. Journal of Counseling Psychology, 61, 221-231. doi: 10.1037/a0035207

Magklara, K., Skapinakis, P., Gkatsa, T., Bellos, S., Araya, R., Stylianidis, S., \& Mavreas, V. (2012). Bullying behaviour in schools, socioeconomic position and psychiatric morbidity: 
A cross-sectional study in late adolescents in Greece. Child \& Adolescent Psychiatry \& Mental Health, 6, 1-13. doi:10.1186/1753-2000-6-8

Menzer, M., \& Torney-Purta, J. (2012). Individualism and socioeconomic diversity at school as related to perceptions of the frequency of peer aggression in fifteen countries. Journal of Adolescence, 35, 1285-1294. doi: 10.1016/j.adolescence.2012.04.013

Mesch, G. S. (2009). Parental mediation, online activities, and cyberbullying. CyberPsychology \& Behavior, 12, 387-393. doi: 10.1089/cpb.2009.0068

Menesini, E., \& Spiel, C. (2012). Introduction: Cyberbullying: Development, consequences, risk and protective factors. European Journal of Developmental Psychology, 9, 163-167. doi: $10.1080 / 17405629.2011 .652833$

Mishna, F., Cook, C., Gadalla, T., Daciuk, J., \& Solomon, S. (2010). Cyber bullying behaviors among middle and high school students. American Journal of Orthopsychiatry, 30, 362-374. doi: 10.1111/j.1939-0025.2010.01040.x

Mishna, F., Cook, C., Saini, M., Wu, M. J., \& MacFadden, R. (2011). Interventions to prevent and reduce cyber abuse of youth: A systematic review. Research on Social Work Practice, 21, 5-14. doi: 10.1177/1049731509351988

Mishna, F., Saini, M., \& Solomon, S. (2009). Ongoing and online: Children and youth's perceptions of cyberbullying. Children and Youth Services Review, 31, 1222-1228. doi: 10.1016/j.childyouth.2009.05.004

Nansel, T. R., Overpeck, M. D., Pilla, R. S., Ruan, W. J., Simons-Morton, B., \& Scheidt, P. (2001). Bullying behaviors among U.S. youth: Prevalence and association with psychosocial adjustment. Journal of the American Medical Association, 16, 2094-2100. doi: 10.1001/jama.285.16.2094. 
Natvig, G. K., Albrektsen, G., \& Qvarnstrom, U. (2001). School-related stress experience as a risk factor for bullying behavior. Journal of Youth and Adolescence, 30, 561-575. doi: 10.1023/A: 1010448604838

Naylor, P., \& Cowie, H. (1999). The effectiveness of peer support systems in challenging school bullying: The perspectives and experiences of teachers and pupils. Journal of Adolescence, 22, 467-479. doi: 10.1006/jado.1999.0241

Neser, J. (2007). The interface between school connectedness and peer victimization: An exploratory study. Acta Criminologica, 20, 55-78.

O’Brennan, L. M., \& Furlong, M. J. (2010). Relations between students' perceptions of school connectedness and peer victimization. Journal of School Violence, 9, 375-391. doi: $10.1080 / 15388220.2010 .509009$

Ortega, R., Ellipe, P., Mora-Merchan, J. A., Genta, M. L., Brighi, A., Guarini, A., Smith, P. K.,...Tippett, N. (2012). The emotional impact of bullying and cyberbullying on victims: A European cross-national study. Aggressive Behavior, 38, 342-356. doi: $10.1002 / \mathrm{ab} .21440$

Owens, L., Daly, A. \& Slee, P. (2005). Sex and age differences in victimization and conflict resolution among adolescents in a South Australian school. Aggressive Behavior 31, 112. doi: 10.1002/ab.20045

Patchin, J. W., \& Hinduja, S. (2008). Bullying beyond the schoolyard: Preventing and responding to cyberbullying. Thousand Oaks, CA: Corwin Press.

Patton, D. U., Eschmann, R. D., \& Butler, D. A. (2013). Internet banging: New trends in social media, gang violence, masculinity and hip hop. Computers in Human Behavior, 29, A54-A59. doi: 10.1016/j.chb.2012.12.035 
Patton, D. U., Hong, J. S., Ranney, M., Patel, S., Kelley, C., Eschmann, R., \& Washington, T. (2014). Social media as a vector for youth violence: A review of the literature. Computers in Human Behavior, 35, 548-553. doi: 10.1016/j.chb.2014.02.043

Peguero, A. A., \& Williams, L. M. (2013). Racial and ethnic stereotypes and bullying victimization. Youth \& Society 45, 545-564. doi: 10.1177/0044118X11424757

Pornari, C. D., \& Wood, J. (2010). Peer and cyber aggression in Secondary school students: The role of moral disengagement, hostile attribution bias, and outcome expectancies. Aggressive Behavior, 36, 81-94. doi: 10.1002/ab.20336

Raskauskas, J., \& Stoltz, A. D. (2007). Involvement in traditional and electronic bullying among adolescents. Developmental Psychology, 43, 564-575. doi: 10.1037/0012-1649.43.3.564

Robers, S., Kemp, J., Rathbun, A., \& Morgan, R. E. (2014). Indicators of School Crime and Safety: 2013 (NCES 2014-042/NCJ 243299). National Center for Education Statistics, U.S. Department of Education and Bureau of Justice Statistics, Office of Justice Programs, U.S. Department of Justice. Washington, DC.

Sasson, H., \& Mesch, G. (2014). Parental mediation, peer norms and risky online behavior among adolescents. Computers in Human Behavior, 33, 32-38. doi: 10.1016/j.chb.2013.12.025

Sawyer, A. L., Bradshaw, C. P., \& O’ Brennan, L. M., (2008). Examining ethnic, gender, and developmental differences in the way children report being a victim of "bullying" on selfreport measures. Journal of Adolescent Health, 43, 106-114. doi: 10.1016/j.jadohealth.2007.12.011

Scholte, R. H. G., Engels, R. C. M. E., Overbeek, G., de Kemp, R. A. T., \& Haselager, G. J. T. (2007). Stability in bullying and victimization and its association with social adjustment 
in childhood and adolescence. Journal of Abnormal Child Psychology, 35, 217-228. doi: $10.1007 / \mathrm{s} 10802-006-9074-3$

Sheridan, S. M., Warnes, E. D., \& Dowd, S. (2004). Home-school collaboration and bullying: An ecological approach to increase social competence in children and youth. In D. L. Espelage \& S. M. Swearer (eds.), Bullying in American schools: A social-ecological perspective on prevention and intervention (pp. 245-268). Mahwah, NJ \& London: Lawrence Erlbaum Associates.

Silva, M. A. I., Pereira, B., Mendonca, D., Nunes, B., \& de Oliveira, W. A. (2013). The involvement of girls and boys with bullying: An analysis of gender differences. International Journal of Environmental Research and Public Health, 10, 6820-6831. doi: 10.3390/ijerph10126820

Smith, P. K., Mahdavi, J., Carvalho, M., Fisher, S., Russell, S., \& Tippett, N. (2008). Cyberbullying: Its nature and impact in Secondary school pupils. Journal of Child Psychology and Psychiatry, 49, 376-385. doi: 10.1111/j.1469-7610.2007.01846.x

Solberg, M. E., \& Olweus, D. (2003). Prevalence estimation of school bullying with the Olweus Bully/Victim Questionnaire. Aggressive Behavior, 29, 239-268. doi: 10.1002/ab.10047

Spriggs, A. L., Iannotti, R. J., Nansel, T. R., \& Haynie, D. L. (2007). Adolescent bullying involvement and perceived family, peer, and school relations: Commonalities and differences across race/ethnicity. Journal of Adolescent Health, 41, 283-293. doi: 10.1016/j.jadohealth/2007.04.009

Stavrinides, P., Nikiforou, N., \& Georgiou, S. (2014). Do mothers know? Longitudinal associations between parental knowledge, bullying, and victimization. Journal of Social and Personal Relationships. doi: 10.1177/0265407514525889 
Storch, E. A., Nock, M. K., Masia-Warner, C., \& Barlas, M. E. (2003). Peer victimization and social-psychological adjustment in Hispanic and African-American children. Journal of Child and Family Studies, 12, 439-452. doi: 10.1023/A:1026016124091

Swearer, S. M., Espelage, D. L., Vaillancourt, T., \& Hymel, S. (2010). What can be done about school bullying? Linking research to educational practice. Educational Researcher, 39, 38-47. doi: 10.3102/0013189X09357622

Sweeting, H., \& West, P. (2001). Being different: Correlates of the experience of teasing and bullying at age 11. Research Papers in Education, 16, 225-246. doi: $10.1080 / 02671520110058679$

Tokunaga, R. S. (2010). Following you home from school: A critical review and synthesis of literature on cyberbullying victimization. Computers in Human Behavior, 26, 277-287. doi: 10.1016/j.chb.2009.11.014

Turner, I., Reynolds, K. J., Lee, E., Subasic, E., \& Bromhead, D. (2014). Well-being, school climate, and the social identity process: A latent growth model study of bullying perpetration and peer victimization. School Psychology Quarterly, 29, 320-335. doi: $10.1037 / \mathrm{spq} 0000074$

Twyman, K., Saylor, C., Taylor, L. A., \& Comeaux, C. (2010). Comparing children and adolescents engaged in cyberbullying to matched peers. Cyberpsychology, Behavior, and Social Networking, 13, 195-199. doi: 10.1089/cyber.2009.0137

Vaillancourt, T., Duku, E., Decatanzaro, D., Macmillan, H., Muir, C. \& Schmidt, L. A. (2008). Variation in hypothalamic-pituitary-adrenal axis activity among bullied and non-bullied children. Aggressive Behavior, 34, 294-305. doi: 10.1002/ab.20240

Varjas, K., Henrich, C. C., \& Meyers, J. (2009). Urban middle school students' perceptions of 
bullying, cyberbullying, and school safety. Journal of School Violence, 8, 159-176. doi: $10.1080 / 15388220802074165$

Verkuyten, M., \& Thijs, J. (2002). Racist victimization among children in the Netherlands: The effect of ethnic group and school. Ethnic and Racial Studies, 25, 310-331. doi: $10.1080 / 01419870120109502$

Wang, J., Iannotti, R. J., \& Nansel, T. R. (2009). School bullying among adolescents in the United States: Physical, verbal, relational, and cyber. Journal of Adolescent Health, 45, 368-375. doi: 10.1016/j.jadohealth.2009.03.021

Wang, J., Nansel, T. R., \& Iannotti, R. J. (2011). Cyber and traditional bullying: Differential association with depression. Journal of Adolescent Health, 48, 415-417. doi: 10.1016/j.jadohealth.2010.07.012

Williams, K. R., \& Guerra, N. G. (2007). Prevalence and predictors of internet bullying. Journal of Adolescent Health, 41, s14-s21. doi: 10.1016/j.jadohealth.2007.08.018

Wilson, D. (2004). The interface of school climate and school connectedness and relationships with aggression and victimization. Journal of School Health, 74, 293-299. doi: 10.1111/j.1746-1561.2004.tb08286.x 
Table 1. Descriptive Statistics of the Study Variables $(N=7,533)$

\begin{tabular}{|c|c|c|c|c|c|}
\hline Variables & $N$ & $\mathrm{n}(\%)$ & $\operatorname{Mean}(S D)$ & Min. & Max. \\
\hline \multicolumn{6}{|l|}{ Individual context } \\
\hline Age & 7,447 & & $14.33(1.38)$ & 11.00 & 17.30 \\
\hline Gender/sex & 7,533 & & & & \\
\hline Male & & $3,596(48.5)$ & & & \\
\hline Female & & $3,937(51.5)$ & & & \\
\hline \multicolumn{6}{|l|}{ Race/ethnicity } \\
\hline European American (non-Hispanic) & & $3,676(50.1)$ & & & \\
\hline African American (non-Hispanic) & & $1,393(20.0)$ & & & \\
\hline Hispanic/Latino & & $1,783(27.1)$ & & & \\
\hline Hours spent on social media & 7,336 & & $2.73(1.34)$ & 1.00 & 9.00 \\
\hline Family SES & 7,389 & & $3.47(0.92)$ & 1.00 & 5.00 \\
\hline \multicolumn{6}{|l|}{ Family context } \\
\hline Parental monitoring $(\alpha=.84)$ & 7,377 & & $2.34(0.50)$ & 1.00 & 3.00 \\
\hline Parent/guardian support $(\alpha=.80)$ & 7,428 & & $2.48(0.50)$ & 1.00 & 3.00 \\
\hline Family satisfaction & 7,490 & & $7.53(2.30)$ & 0.00 & 10.00 \\
\hline Peer groups accepted by parents & 7,499 & & $2.56(0.66)$ & 1.00 & 3.00 \\
\hline \multicolumn{6}{|l|}{ Friend/peer context } \\
\hline Time spent with friends & 7,487 & & $5.07(3.48)$ & 0.00 & 13.00 \\
\hline Calling/texting friends & 7,512 & & $3.39(1.52)$ & 1.00 & 5.00 \\
\hline \multicolumn{6}{|l|}{ School context } \\
\hline Feelings about school & 7,495 & & $2.84(0.89)$ & 1.00 & 4.00 \\
\hline Perceived peer support in school $(\alpha=.71)$ & 7,469 & & $3.53(0.87)$ & 1.00 & 5.00 \\
\hline Schoolwork pressure & 7,461 & & $2.58(1.00)$ & 1.00 & 4.00 \\
\hline \multicolumn{6}{|l|}{ Dependent variables } \\
\hline Face-to-face bullying victimization $(\alpha=.83)$ & 7,533 & & & & \\
\hline None & & $3,469(46.1)$ & & & \\
\hline Only once or twice & & $3,124(41.5)$ & & & \\
\hline 2 or 3 times a month & & $640(8.5)$ & & & \\
\hline About once a week & & $215(2.9)$ & & & \\
\hline Several times a week & & $85(1.1)$ & & & \\
\hline Cyberbullying victimization $(\alpha=.79)$ & 7,533 & & & & \\
\hline None & & $6,779(90.0)$ & & & \\
\hline Only once or twice & & $451(6.0)$ & & & \\
\hline 2 or 3 times a month & & $160(2.1)$ & & & \\
\hline About once a week & & $67(0.9)$ & & & \\
\hline Several times a week & & $76(1.0)$ & & & \\
\hline
\end{tabular}

Note. Sample sizes are unweighted. Other analyses are weighted to be nationally representative. 
Table 2. Bivariate Correlation Coefficients for All Variables

\begin{tabular}{|c|c|c|c|c|c|c|c|c|c|c|c|c|c|c|c|c|c|c|}
\hline & 1 & 2 & 3 & 4 & 5 & 6 & 7 & 8 & 9 & 10 & 11 & 12 & 13 & 14 & 15 & 16 & 17 & 18 \\
\hline \multicolumn{19}{|l|}{ 1. Age } \\
\hline 2. Female & $-.03 *$ & & & & & & & & & & & & & & & & & \\
\hline 3. European American & .02 & $-.03 *$ & & & & & & & & & & & & & & & & \\
\hline 4. African American & $.04 *$ & .01 & $-.42 *$ & & & & & & & & & & & & & & & \\
\hline 5. Hispanic/Latino & $-.05 *$ & $.03 *$ & $-.43 *$ & $-.18 *$ & & & & & & & & & & & & & & \\
\hline 6. Hours spent on social media & $.10^{*}$ & $.10^{*}$ & $.03 *$ & .01 & $-.05^{*}$ & & & & & & & & & & & & & \\
\hline 7. Family SES & $-.04 *$ & $-.07 *$ & $.08^{*}$ & $-.06^{*}$ & $-.05^{*}$ & -.02 & & & & & & & & & & & & \\
\hline 8. Parental monitoring & $-.13 *$ & $-.05^{*}$ & $.18^{*}$ & $-.16^{*}$ & $-.07 *$ & $-.04 *$ & $.26^{*}$ & & & & & & & & & & & \\
\hline 9. Parent/guardian support & $-.11 *$ & $-.04 *$ & $.12 *$ & $-.07 *$ & $-.07^{*}$ & $-.04 *$ & $.28^{*}$ & $.49^{*}$ & & & & & & & & & & \\
\hline 10. Family satisfaction & $-.13 *$ & $-.15^{*}$ & $.04 *$ & $-.04 *$ & $-.03 *$ & $-.09^{*}$ & $.38^{*}$ & $.47^{*}$ & $.62 *$ & & & & & & & & & \\
\hline 11. Peer groups accepted by parents & $-.14 *$ & $.03 *$ & $.15^{*}$ & $-.09 *$ & $-.08 *$ & -.02 & $.19^{*}$ & $.36^{*}$ & $.38^{*}$ & $.36^{*}$ & & & & & & & & \\
\hline 12. Time spent with friends & $.04 *$ & $.08^{*}$ & $-.06^{*}$ & $.08^{*}$ & -.01 & $.09 *$ & .00 & $-.09 *$ & $.04 *$ & $.04 *$ & $.08^{*}$ & & & & & & & \\
\hline 13. Calling/texting friends & $.15^{*}$ & $.21 *$ & $.10^{*}$ & .02 & $-.12 *$ & $.33^{*}$ & .01 & $-.03 *$ & -.00 & $-.05 *$ & $.09 *$ & $.26^{*}$ & & & & & & \\
\hline 14. Feelings about school & -.07 & $.05^{*}$ & $-.03 *$ & .00 & .01 & $-.09 *$ & $.18^{*}$ & $.25^{*}$ & $.26^{*}$ & $.29 *$ & $.20^{*}$ & $-.04 *$ & $-.04 *$ & & & & & \\
\hline 15. Perceived peer support in school & -.01 & $-.04 *$ & $.03 *$ & $-.03 *$ & -.02 & -.01 & $.17^{*}$ & $.21^{*}$ & $.24^{*}$ & $.28^{*}$ & $.19^{*}$ & $.08^{*}$ & $.08^{*}$ & $.26^{*}$ & & & & \\
\hline 16. Schoolwork pressure & $.08^{*}$ & $.10^{*}$ & $.05^{*}$ & $-.08 *$ & .00 & $.08^{*}$ & $-.09 *$ & $-.07 *$ & $-.12 *$ & $-.17 *$ & $-.05^{*}$ & $-.04 *$ & $.10^{*}$ & $-.19 *$ & $-.08 *$ & & & \\
\hline 17. Face-to-face bullying victimization & $-.12 *$ & -.02 & $-.05^{*}$ & $.04 *$ & .01 & $.05^{*}$ & $-.10^{*}$ & $-.11 *$ & $-.14 *$ & $-.17 *$ & $-.11 *$ & $-.03 *$ & $-.05^{*}$ & $-.12 *$ & $-.26^{*}$ & $.10^{*}$ & & \\
\hline 18. Cyberbullying victimization & $-.03 *$ & $-.02 *$ & $-.06 *$ & $.05^{*}$ & $.03^{*}$ & $.07 *$ & $-.04 *$ & $-.09 *$ & $-.09 *$ & $-.08 *$ & $-.08 *$ & $.04 *$ & .02 & $-.09 *$ & $-.11 *$ & $.03 *$ & $.57^{*}$ & \\
\hline
\end{tabular}

$* p<.05$ 
Table 3. Factor Analysis

\begin{tabular}{|c|c|c|c|}
\hline Variable & Family & Friend/Peer & School \\
\hline Parental monitoring & .77 & & \\
\hline Parent/guardian support & .80 & & \\
\hline Family satisfaction & .75 & & \\
\hline Peer groups accepted by parents & .67 & & \\
\hline Time spent with friends & & .79 & \\
\hline Calling/texting friends & & .77 & \\
\hline Feelings about school & & & .62 \\
\hline Perceived peer support in school & & & .45 \\
\hline Schoolwork pressure & & & -.81 \\
\hline Eigenvalue & 2.76 & 1.33 & 1.05 \\
\hline$\%$ Variance explained & 30.66 & 14.79 & 11.67 \\
\hline
\end{tabular}

Note. Final factor loading from principal component analysis with varimax rotation of composite subscales. Together, the factors explain $57.13 \%$ of the variance. 
Table 4. OLS Regressions Predicting Face-to-Face Bullying and Cyberbullying Victimizations by the Individual, and Family,

Friend/Peer, and School Contexts

\begin{tabular}{|c|c|c|c|c|}
\hline & \multicolumn{2}{|l|}{ Model $1(95 \% \mathrm{CI})$} & \multicolumn{2}{|l|}{ Model 2 $(95 \% \mathrm{CI})$} \\
\hline & Face-to-face bullying & Cyberbullying & Face-to-face bullying & Cyberbullying \\
\hline Age & $-.13(-.07,-.05)^{* * *}$ & $-.04(-.03,-.01)^{* * * *}$ & $-.16(-.08,-.06)^{* * * *}$ & $-.05(-.03,-.01)^{* * * *}$ \\
\hline Female & $-.03(-.07, .-01)^{* *}$ & $-.03(-.05, .-01)^{*}$ & $-.05(-.09,-.03)^{* * *}$ & $-.03(-.05,-.00)^{*}$ \\
\hline European American & $-.04(-.09,-.01)^{*}$ & $-.03(-.06, .00)$ & $-.04(-.09,-.01)^{*}$ & $-.02(-.05, .02)$ \\
\hline African American & $.02(-.02, .07)$ & $.04(.02, .09)^{* *}$ & $-.01(-.06, .03)$ & $.02(-.01, .07)$ \\
\hline Hispanic/Latino & $-.01(-.06, .03)$ & $.02(-.01, .06)$ & $-.03(-.08, .00)$ & $.01(-.02, .04)$ \\
\hline Hours spent on social media & $.07(.02, .04)^{* * *}$ & $.08(.01, .03)^{* * *}$ & $.05(.01, .03)^{* * *}$ & $.07(.01, .03)^{* * * *}$ \\
\hline Family SES & $-.10(-.10,-.05)^{* * * *}$ & $-.03(-.03,-.01)^{* *}$ & $-.03(-.04,-.01)^{* *}$ & $-.01(-.02, .01)$ \\
\hline Parental monitoring & & & $-.05(-.10,-.02)^{* *}$ & $-.06(-.08,-.03) * * *$ \\
\hline Parent/guardian support & & & $-.02(-.06, .02)$ & $-.03(-.06, .01)$ \\
\hline Family satisfaction & & & $-.12(-.04,-.02)^{* * * *}$ & $.01(-.01, .01)$ \\
\hline Peer groups accepted by parents & & & $-.04(-.06,-.01)^{* *}$ & $-.03(-.04,-.00)^{*}$ \\
\hline \multicolumn{5}{|l|}{ Time spent with friends } \\
\hline \multicolumn{5}{|l|}{ Calling/texting friends } \\
\hline \multicolumn{5}{|l|}{ Feelings about school } \\
\hline \multicolumn{5}{|l|}{ Perceived peer support in school } \\
\hline \multicolumn{5}{|l|}{ Schoolwork pressure } \\
\hline$N$ & 7,007 & 7,007 & 6,787 & 6,787 \\
\hline$R^{2}$ & .04 & .02 & .06 & .02 \\
\hline $\mathrm{F}$ & $32.99 * * *$ & $12.77 * * *$ & $38.02 * * *$ & $10.93 * * *$ \\
\hline
\end{tabular}

Note. OLS regression = ordinary least squares regression; $\mathrm{CI}=$ confidence interval. Confidence intervals are based on unstandardized coefficients.

$* p<.05 . * * p<.01 . * * * p<.001$. 
Table 4. (Continued)

\begin{tabular}{|c|c|c|c|c|}
\hline & \multicolumn{2}{|l|}{ Model $3(95 \% \mathrm{CI})$} & \multicolumn{2}{|l|}{ Model 4 $(95 \% \mathrm{CI})$} \\
\hline & Face-to-face bullying & Cyberbullying & Face-to-face bullying & Cyberbullying \\
\hline Age & $-.15(-.08,-.06)^{* * * *}$ & $-.06(-.03,-.01)^{* * * *}$ & $-.15(-.08,-.06)^{* * * *}$ & $-.05(-.03,-.01)^{* * * *}$ \\
\hline Female & $-.04(-.09,-.02)^{* * * *}$ & $-.03(-.06,-.01)^{*}$ & $-.05(-.09,-.03)^{* * *}$ & $-.03(-.05,-.00)^{*}$ \\
\hline European American & $-.04(-.08,-.01)^{*}$ & $-.02(-.05, .01)$ & $-.05(-.10,-.02)^{* *}$ & $-.03(-.06, .01)$ \\
\hline African American & $-.01(-.06, .03)$ & $.02(-.01, .06)$ & $-.00(-.05, .04)$ & $.02(-.02, .06)$ \\
\hline Hispanic/Latino & $-.03(-.08,-.00)^{*}$ & $.01(-.02, .04)$ & $-.03(-.08,-.00)^{*}$ & $.01(-.03, .04)$ \\
\hline Hours spent on social media & $.07(.01, .03)^{* * *}$ & $.06(.01, .03)^{* * *}$ & $.06(.01, .03)^{* * *}$ & $.06(.01, .03)^{* * *}$ \\
\hline FamilySES & $-.03(-.04,-.01)^{*}$ & $-.01(-.02, .01)$ & $-.02(-.03, .00)$ & $-.00(-.02, .01)$ \\
\hline Parental monitoring & $-.06(-.08,-.01)^{*}$ & $-.05(-.08,-.03)^{* * * *}$ & $-.04(-.08,-.01)^{*}$ & $-.04(-.07,-.01)^{* *}$ \\
\hline Parent/guardian support & $-.01(-.06, .02)$ & $-.03(-.06, .00)$ & $.01(-.03, .05)$ & $-.02(-.05, .01)$ \\
\hline Family satisfaction & $-.12(-.04,-.02) * * *$ & $.01(-.01, .01)$ & $-.09(-.03,-.02)^{* * *}$ & $.02(-.00, .01)$ \\
\hline Peer groups accepted by parents & $-.03(-.06,-.01)^{*}$ & $-.03(-.05,-.01)^{*}$ & $-.02(-.04, .01)$ & $-.03(-.04,-.00)^{*}$ \\
\hline Time spent with friends & $-.03(-.01,-.00)^{*}$ & $.02(-.00, .01)$ & $-.01(-.01, .00)$ & $.02(.00, .01)$ \\
\hline Calling/texting friends & $-.04(-.04,-.00)^{* *}$ & $.02(-.00, .02)$ & $-.03(-.02, .00)$ & $.03(.00, .02)^{*}$ \\
\hline Feelings about school & & & $-.03(-.04,-.00)^{*}$ & $-.06(-.05,-.02) * * *$ \\
\hline Perceived peer support in school & & & $-.19(-.16,-.12)^{* * *}$ & $-.06(-.04,-.02) * * *$ \\
\hline Schoolwork pressure & & & $.06(.02, .05)^{* * * *}$ & $-.02(-.02, .00)$ \\
\hline$N$ & 6,764 & 6,764 & 6,670 & 6,670 \\
\hline$R^{2}$ & .06 & .02 & .11 & .03 \\
\hline $\mathrm{F}$ & $33.60 * * *$ & $9.45^{* * * *}$ & $47.02 * * *$ & $10.59 * * *$ \\
\hline
\end{tabular}

Note. OLS regression = ordinal least square regression; $\mathrm{CI}=$ confidence interval. Confidence intervals are based on unstandardized coefficients.

$* p<.05 . * * p<.01 . * * * p<.001$. 